\title{
Antiglycation and antioxidant activity of four Iranian medical plant extracts
}

\author{
Mohammad Reza Safari', Omid Azizi², Somayeh Sadat Heidary³, Nejat Kheiripour ${ }^{3}$, \\ Alireza Pouyandeh Ravan*1
}

\begin{abstract}
${ }^{1}$ Department of Medical Laboratory Sciences, School of Para Medicine, Hamadan University of Medical Sciences, Hamadan, Iran. Safarimr2000dyahoo.com, A.r.pouyandeh.ravandgmail.com.

2 Department of Basic Sciences, Torbat Heydariyeh University of Medical Sciences, Torbat Heydariyeh, Iran. Omid201262@gmail.com

${ }^{3}$ Department of Biochemistry, School of Medicine, Hamadan University of Medical Sciences, Hamadan, Iran. Somayesadat_heidaryla yahoo.com, nejatkh.biodgmail.com.
\end{abstract}

\section{Key Words}

Diabetes mellitus, Glycosylation, Antioxidants

\begin{abstract}
Objective: Diabetes mellitus (DM) is the most common metabolic disorder that defined by chronic hyperglycemia for the deficiency in insulin secretion or resistance. Hyperglycemia could induce non-enzymatic glycation of proteins. It has been suggested that some traditional plants can improve blood glucose and inhibit glycation process. This work evaluates and compares the anti-glycation activities of four Iranian plant extracts in vitro.
\end{abstract}

Methods: The methanolic extract of "Fumaria officinalis, Stachys lavandulifolia, Salvia hydrangea and Rosa Damascene" was prepared in three different concentrations. Phenolic, flavonoids content and antioxidant activity were evaluated. The multistage glycation markers- fructosamines (early stage), protein carbonyls (intermediate stage) and $\otimes$ aggregation of albumin were investigated in the bovine serum albumin (BSA)/ glucose systemt.

Results: All plants showed the high potency of scav-

Received: Dec 21, 2017 Reviewed: Mar 20, 2018 Accepted: May 17, 2018

(c) This is an Open-Access article distributed under the terms of the Creative Common Attribution Non-Commercial License (http://creativecommons.org/licenses/by-nc/4.0/) which permits unrestricted noncommercial use, distribution, and reproduction in any medium, provided the original work is properly cited.

( $)$ This paper meets the requirements of KS X ISO 9706, ISO 9706-1994 and ANSI/NISO Z39.48-1992 (Permanence of Paper). enging free radicals and glycation inhibition in the following order: Fumaria officinalis> Rosa Damascene> Stachys lavandulifolia > Salvia hydrangea. There was a significant correlation between antioxidant and anti-glycation activity. Also, the antioxidant and anti-glycation capacity of extracts correlated with total phenolic and flavonoids content.

Conclusion: Our findings demonstrated that the studied plants are good sources of anti-glycation and antioxidant compounds and, these properties can primarily attributable to phenolics, particularly flavonoids.

\section{Introduction}

Diabetes mellitus (DM) is a metabolic disorder characterized by hyperglycemia. Prevalence of diabetes and its associated complications has been rising in the last few decades dramatically and leads to substantial morbidity and premature mortality and remains a major risk factor for cardiovascular disease worldwide [1]. Chronic hyperglycemia is the major factor responsible for vascular and organ complications in diabetes[2]. Uncontrolled excess blood glucose reacts with free amino acids of proteins to form a labile Schiff's base and stabilizes in a compound known as 
advanced glycation end products (AGEs) [3]. Glycation of proteins induce several structural modifications and modify the function of many proteins especially albumin. This process affects the affinity of albumin binding activity of drugs, hormones, fatty acids and other small solutes $[4,5]$. In addition, it has been shown that albumin-derived AGEs, triggers the generation of intracellular reactive oxygen species (ROS) leading to glucose uptake inhibition and oxidative alteration of intracellular proteins [6]. Albumin has the ability to scavenge free radicals relying on its structure and, this protective feature is lost in the condition of uncontrolled diabetes [7]. Numerous AGEs inhibitors including pharmacological and natural compounds have been investigated for their potentials of impeding diabetes complications but, medicinal plants are proposed to be safer than others and many of them have the property of reducing harmful effects of hyperglycemia [8]. Fumaria officinalis (Fumariaceae) is a widespread perennial herb in Asia and Europe which has played a traditional role in empirical medicine such as treatment of skin diseases, rheumatism, hypertension or infections over centuries. Stachys lavandulifolia is grown in many parts of Iraq, Iran, and Anatolia. This plant is known as Chaye-kuhi in Iran and used as the herbal tea in gastrointestinal disorder [9]. Salvia species such as Salvia hydrangea (endemic to Iran) are rich in phenolic flavonoids and phenolic acids. Many of compounds in the species of this genera have antioxidant properties which act through enzymatic and non-enzymatic pathways [9-11]. Rosa damascene, known as Persian rose, is an erect shrub from the Rosaceae family. The antibacterial, anti-HIV, and antioxidant activities of the essential oil of Rosa damascena have been demonstrated [12]. Fumaria officinalis, Stachys lavandulifolia, Salvia hydrangea and Rosa damascene have long been used in traditional medicine in Iran, and their hypoglycemic effects in diabetes have been proven [13-15].

The objective of present study was to investigate the anti-glycation potential of these plant extracts. The multistage glycation markers fructosamines (early stage), protein carbonyls (intermediate stage) and $\otimes$ aggregation of albumin using amyloid-specific dyes-Congo red are investigated. In addition, correlation of antiglycative effects with the extracts total phenolics, and antioxidant potential is also evaluated.

\section{Materials and Methods}

\subsection{Chemical}

All chemicals were of analytical grade: Bovine serum albumin (BSA), 2, 2-diphenyl-1- picrylhydrazyl (DPPH), 2, 4-dinitrophenylhydrazine (DNPH), Thiobarbituric acid (TBA), Congo red, Trichloroacetic acid (TCA), Ethyl acetate and Gentamicin sulfate were purchased from Sigma Aldrich Chemical Company (Poole, UK). Glucose, Urea, and Ethyl alcohol were obtained from Carlo Erba (Carlo Erba Reagenti, Rodano, Milano, Italy). Methanol, Ethylenediaminetetraacetic acid (EDTA) and Hydrochloric acid ( $\mathrm{HCl})$ were purchased from Merck (Darmstadt, Germany).

\subsection{Plant material and extract preparation}

The plants were purchased from the medical and clinical centers. Aerial parts of plants collected and impurities removed, $500 \mathrm{~g}$ of the plants were washed, dried at room temperature, ground into powder and mixed with methanol $75 \%$ by the ratio of 1 to 10 . Twenty-four hours later, the solution was filtered and dried at $37^{\circ} \mathrm{C}$. Concentrations of $0.5,0.25$ and $0.12 \mathrm{~g} / \mathrm{dl}$ in distilled water were prepared and used for subsequent measurements [15].

\subsection{Antioxidant activity determinations}

The antioxidant activity of the extracts was measured by investigating their ability to scavenge the DPPH free radical method as described previously with slight modifications [16]. Briefly, $0.1 \mathrm{ml}$ of each extract at different concentrations (in distilled water) was added to $4 \mathrm{ml}$ of a DPPH solution ( $50 \mu \mathrm{M}$ in ethanol) as the free radical source and incubated for $10 \mathrm{~min}$ at RT. The reduction in the solution absorbance, due to proton donating property by component(s), was measured at $517 \mathrm{~nm}$ using UV-VIS spectrophotometer ( $\alpha-1860$ Split beam UV/Visible spectrophotometer, China). The DPPH radical reduction percentage was calculated from the following formula:

\%scavenging $[\mathrm{DPPH}]=[(\mathrm{A} 0-\mathrm{A} 1) / \mathrm{A} 0] \times 100$

A0: The absorbance of sample without extract, A1: The absorbance of sample in the presence of extract

\subsection{Determinations of total phenolic}

Total phenolic contents were determined by Folin-Ciocalteau method as described previously with some modifications [17]. Briefly, extracts were reconstituted in d H2O (1 $\mathrm{mg} / \mathrm{ml}$ ). $500 \mu \mathrm{l}$ of each extract or standard solution was added to $2.8 \mathrm{ml}$ of $\mathrm{d} \mathrm{H}_{2} \mathrm{O}$ and $100 \mu \mathrm{l}$ of freshly prepared $50 \%$ Folin-Ciocalteau phenol reagent. Rapidly $1 \mathrm{ml}$ of $20 \% \mathrm{Na}_{2} \mathrm{CO}_{3}$ was added to the mixture. The test tubes were incubated in a water bath at $30^{\circ} \mathrm{C}$ for $90 \mathrm{~min}$. Absorbance was measured at $750 \mathrm{~nm}$ using a UV-visible spectrophotometer. Distilled water was used as the reagent blank. For quantification of the total phenolic in the extracts, the Gallic acid standard curve was obtained from the absorbance of different concentrations (0-200 mg/l). Total phenolic content of the extracts was expressed as mg of Gallic acid equivalent (GAE) per 100 grams of extracts (mg GAE/100 g EX).

\subsection{Determinations of flavonoid content}

Flavonoids content determination of each extract was performed according to the Aluminum chloride colorimetric method with some modifications [17]. Briefly, $1 \mathrm{ml}$ of $\mathrm{d} \mathrm{H}_{2} \mathrm{O}$ was added to $100 \mu \mathrm{l}$ of each extract or standard solution and $100 \mu \mathrm{l}$ of $5 \% \mathrm{NaNO}_{2}$. After $6 \mathrm{~min}, 100 \mu \mathrm{l}$ of $10 \%$ $\mathrm{AlCl}_{3}$ was added and was incubated at room temperature for $6 \mathrm{~min}$, and then $100 \mu \mathrm{l}$ of $\mathrm{NaOH}(1 \mathrm{M})$ was added to the mixtures. The volume of reaction mixtures was adjusted to $2.5 \mathrm{ml}$ with $\mathrm{d} \mathrm{H}_{2} \mathrm{O}$. The test tubes were thoroughly mixed and the absorbance of the developed pink color was measured at $510 \mathrm{~nm}$. Using a point standard curve of Quercetin (0-50 mg/l), total flavonoid content was determined and expressed as mg quercetin per $100 \mathrm{~g}$ of extracts (mg QE/100 g EX). 


\subsection{Albumin glycation}

Albumin glycation was performed, according to the method described by McPherson et al. with slight modifications [18]. Briefly, a $3.5 \mathrm{ml}$ of total volume of glycation reaction solution includes different extract solutions $(0.5 \mathrm{ml}), 5 \%$ BSA ( $1 \mathrm{ml})$, glucose $(1 \mathrm{ml}, 166.5 \mathrm{mM})$ and gentamicin (1 $\mathrm{ml}, 20 \mathrm{mg} / \mathrm{dl}$ in phosphate buffer $0.01 \mathrm{M}$ and $\mathrm{pH}:$ 7.4). All solutions were sterilized through $0.22 \mu \mathrm{m}$ pore size filter. Following incubation at $37{ }^{\circ} \mathrm{C}$ for $72 \mathrm{~h}$, all the solutions were ensured to be free of microbiological contamination. Finally, the solutions were dialyzed extensively against phosphate buffer and the extra-unbound glucose and any other impurities were removed from the solutions.

\subsection{Estimation of fructosamine production}

To evaluate the fructosamine production, Thiobarbituric acid (TBA) assay was used according to the protocol described previously [15]. For this purpose, $1 \mathrm{ml}$ of $20 \%$ Trichloroacetic acid (TCA) was added to $1 \mathrm{ml}$ of glycated samples, the precipitate washed three times at $6000 \mathrm{~g}$ for $10 \mathrm{~min}$, solubilized in $1 \mathrm{ml}$ phosphate buffer and added to $0.5 \mathrm{ml} 40 \% \mathrm{TCA}$. Following centrifugation at $6000 \mathrm{~g}$ for 10 min, $0.5 \mathrm{ml}$ of supernatant was mixed with TBA $(0.05 \mathrm{M})$. The mixtures were incubated in a boiling water bath for 20 min, cooled to room temperature and the absorbance was read at the $443 \mathrm{~nm}$. Inhibition of fructosamine was calculated as a percentage using the following formula:

$$
\text { Inhibitory activity }(\%)=[(\mathrm{A} 0-\mathrm{A} 1) / \mathrm{A} 0] \times 100
$$

A0: absorbance of positive control group, Al: absorbance in presence of the extract sample.

\subsection{Estimation of carbonyl groups}

The method of Uchida et al was chosen for albumin carbonyl compounds estimation with slight modifications [19]. In brief, an equal volume $(0.5 \mathrm{ml})$ of glycated samples and DNPH (10 mM in HCL 2.5 M) were placed in glass tubes and incubated for one hour at room temperature. Proteins of the solution were precipitated by adding $0.5 \mathrm{ml}$ of TCA $20 \%$ and the pellet was washed by ethanol-ethyl acetate $(1: 1 \mathrm{v} / \mathrm{v})$ for three times and dissolved in $1 \mathrm{ml}$ of $6 \mathrm{M}$ urea. The UV absorbance was recorded at $365 \mathrm{~nm}$ and the carbonyl concentration was calculated by using the molar extinction coefficient of DNPH $(\varepsilon 365 \mathrm{~nm}=21 \mathrm{mM}$ per $\mathrm{cm}$ ). The percentage of inhibition was calculated as follow:

$$
\text { Inhibition \% }=[1-(\mathrm{A} 0-\mathrm{A} 1) / \mathrm{A} 0] \times 100
$$

A0: absorbance of positive control group, Al: absorbance in presence of the extract sample

\subsection{Estimation of amyloid $\beta$-structures}

Congo red binding to $\beta$-amyloid aggregation in the samples was estimated by measuring absorbance at $530 \mathrm{~nm}$ [20]. Accordingly, $0.5 \mathrm{ml}$ of glycated albumin was mixed with $100 \mu \mathrm{l}$ of Congo red $(100 \mathrm{Mm}$ solution in phosphate-buffered saline, $10 \%$ ethanol) and incubated for 20 min at room temperature. The absorbance was measured at $530 \mathrm{~nm}$. The percentage of inhibition measured by the following equation:

$$
\text { Inhibition \% }=[1-(\mathrm{A} 0-\mathrm{A} 1) / \mathrm{A} 0] \times 100
$$

A0: absorbance of positive control group, Al: absorbance in presence of the extract sample

\subsection{Total inhibition of glycation reaction}

To evaluate the total inhibition of glycation for each extract, IC $\mathrm{C}_{5} 0$ was calculated for TBA, DNPH and Congo red dye methods and the average was expressed as Mean \pm S.E.M.

\subsection{Statistical analysis}

All experimental data were obtained from at least 3 independent tests for each extract and presented as mean \pm SEM. The significance of differences between treatments was tested by ANOVA (Tukey test), using SPSS 16 software. Correlation between two variants was analyzed by Pearson test. Significance value was set at $\mathrm{p}<0.05$.

\section{RESULTS}

Total phenol and flavonoid content and, the antioxidant activity of the extracts are summarized in table 1 . The most amounts of phenol and flavonoid content were found in Fumaria officinalis and the lowest amount was obtained from Salvia hydrangea. The result of the antioxidant capacity evaluation of each plant extract by DPPH radical cleaning method was expressed as $\mathrm{IC}_{5} 0$. Similar to phenol and flavonoid results, Fumaria officinalis and Salvia hydrangea showed the highest (IC50: $122.38 \pm 8.57$ ) and lowest (234.38 \pm 13.73) antioxidant capacity respectively. The results shown in Table 2 indicate that all extracts inhibited albumin glycation at three stages: fructosamine generation (TBA),

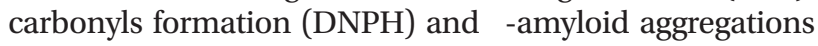
(Congo red). The manner of inhibition was dose-dependent and the most effective dose for each extract was 0.5 $\mathrm{gr} / \mathrm{dl}$. In addition, at the same concentration, the inhibitory results were significantly different for each extract as compared to the others. Accordingly, it was found that Fumaria officinalis had the maximum (IC50: $1.04 \pm 0.05$, IC50: $1.44 \pm 0.02$ ) and Salvia hydrangea exerted the minimum inhibitory effects (IC50: $1.66 \pm 0.02$, IC $50: 2.91 \pm 0.15$ ) on fructosamine and carbonyls formation respectively. Interestingly, in the case of $\beta$-amyloid aggregations, results were different. The highest inhibition of $\beta$-amyloid aggregations belonged to Fumaria officinalis again ( $\mathrm{IC}_{5} 0: 0.002 \pm 0.002$ ), but at this stage, Stachys lavandulifolia have the lowest inhibitory effects (IC50: 1.41 0.5).

Total inhibitory property of glycation for each extract regardless the level and rate of inhibition were shown in table 3.

Total glycation inhibition indicates the overall inhibition of extract obtained from TBA, DNPH and Congo red methods. Cumulatively, the most promising effect against glycation was observed in the presence of Fumaria officinalis ( $\mathrm{IC}_{5} 0$ : $0.83 \pm 0.01$ ) and in Salvia hydrangea least anti- 
glycation activities were detected ( $\mathrm{IC}_{5} 0: 1.95 \pm 0.05$ ).

The correlative analysis demonstrated that total anti-glycation activity or TBA, DNPH and Congo red reactions for a particular extract was strongly correlated with its antioxidant capacity (DPPH-radical scavenging) (Table 4). Like antioxidant capacity, anti-glycation activity was strongly correlated with phenolic and flavonoid contents (table 5).

\section{DISCUSSION}

Long-standing hyperglycemia in DM can change proteins structures in both tissues and serum. Alteration in protein structure is due to the non-enzymatic glycation activity of proteins and leading to malfunction of proteins [6]. Many attempts have been made to prevent the process of protein glycation and some of them were made in the field of herbal medicines. In traditional medicine, some medicinal plants have been observed to attenuate hyperglycemia in diabetes mellitus [21]. In the present study, we evaluated inhibition activity of four Iranian medicinal plant extracts on albumin glycation, in vitro. First, we examined the antioxidant capacity. Our findings showed that Fumaria officinalis, Rosa Damascene, Stachys lavandulifolia and Salvia hydrangea have the highest amount of phenolic and flavonoid compounds and antioxidant capacity respectively. In addition, phenol concentration was more than flavonoids in all extracts. Pearson correlative analysis indicated that there is a significant correlation between the antioxidant capacity and the phenolic $(\mathrm{P}=0.000)$ and flavonoid content $(\mathrm{P}=0.001)$ in the extracts. Persistent hyperglycemia induces a condition of oxidative stress by oxidization of excess glucose and generation of ROS [22]. Protein derivatives such as carbonyls and modified amino acids arise from direct attack of ROS. The strategy of applying antioxidant has been extensively studied and their protective effects against free radical damages are approved [23]. In our investigation, all extracts showed antioxidant activity but, the best potential of antioxidant and scavenging free radicals were achieved with Fumaria officinalis. This was consistent with the results of other studies. Ivanov et al. found that officinalis has the highest amount of phenolic content and antioxidant properties among other species of Fumaria [24]. Also, Rosa damascene, Stachys lavandulifolia, and Salvia hydrangea have been demonstrated to be a good resource of antioxidants due to the content of phenolic and flavonoids compounds [25-27].

Phenols and flavonoids are categorized as antioxidants and their protective effects in diabetes have been reported. Some studies indicate the more content of phenol and flavonoids have more effects on hyperglycemic protection [28]. The findings of our study showed such effects. Glycation of albumin including the formation of fructosamine, carbonyl groups, and amyloid $\beta$-structures, significantly attenuated in the presence of extracts. The initial step of AGEs formation also known as the Maillard reaction starts up through nucleophilic attachment reaction of free amino groups of proteins with the carbonyl group of reducing sugars to form reversibly a Schiff base product, which in turn convert to stable fructosamine residue (ketoamine) by an Amador rearrangement. Schiff's base and fructosamines have been named early glycation products.
These adducts could undergo subsequent oxidation, rearrangement, dehydration, and cyclization to form stable agents called advanced glycation end products AGEs. AGEs are extremely reactive irreversibly bound complex structures that continue to react with nearby amino groups of proteins to generate intra- and intermolecular crosslinks [29-32]. It has been demonstrated that AGEs inhibitors can impede the generation of reactive dicarbonyls and oxygen species [6]. Antioxidants such as phenols and flavonoids have been suggested that inhibit AGEs formation and such properties have been attributed to the structure of these compounds. Actually, adjacent $\mathrm{OH}$-groups identified to be responsible for their antioxidant and anti-glycation activity [33, 34]. The association between antioxidant and antiglycation activity was apparent in the way that maximum glycation inhibition was assigned to Fumaria officinalis which showed the highest antioxidant property. Salvia hydrangea exhibited the lowest power in the prevention of fructosamine and carbonyl formation, so we expected to observe the similar effect in Congo red experiment but, the result was different and Stachys lavandulifolia with more antioxidant capacity than Salvia hydrangea, showed the lowest ability to prevent amyloid $\beta$-structures formation. This property can be justified due to some evidence. It has been shown that despite the existence of an association between antioxidant content and antiglycation capacity $[15,35,36]$, some plants with strong antiglycation activity possess low antioxidant activity [36]. The result of our study indicates that all extracts were able to remove free radicals and prevent albumin glycation and these properties were strongly correlated with each other. We also examined three different concentrations of 0.5, 0.25 and $0.12 \mathrm{gr} / \mathrm{dl}$ in all Experiments. Our findings demonstrated that more concentration for each extract will result in more inhibition of albumin glycation. Therefore, it seems that the ability of antioxidant and antiglycation of plants was due to phenolic and flavonoid concentration.

Previously, Fathiazad, Gholamhoseinian, and Zarei et al showed that administration of Fumaria parviflora, Rosa damascene, and Salvia hydrangea has a significant hypoglycemic effect on streptozotocin-induced diabetic rats $[13,27]$. Also, Rahzani et al suggested that Stachys lavandulifolia has a strong capacity in reducing oxidative stress and managed to be useful in diseases related to the accumulation of free radicals [37]. According to these results and medical history of plants studied in the present study, positive effects of the extracts on reducing albumin glycation were not unexpected and their antiglycation activity was demonstrated.

Although for several synthetic AGEs inhibitors hopeful advances have been obtained in vitro and in animal models, still most of the clinical trials have been more or less unsatisfactory in part because of unpredicted side-effects. Thus, petition for natural or herbal agents has increased in diabetics.

\section{Conclusion}

In conclusion, our result's support the opinion that anti- 
diabetic herbs are reasonable agents to inhibit oxidative stress and glycation. Based on their anti-glycation capacities, we suggest that the consumption of plant extracts may promote the health of the diabetics by discounting AGEs- induced complications. These new outcomes offer evidence for a novel mechanism by which antidiabetic traditional plants might have extra protective effects and lay the foundation for future in vivo investigations against diabetic complications.
This study was financially supported by Hamadan University of Medical Sciences (Grant No. 9303131155).

\section{Conflict of Interests}

The authors declared no competing interests.

\section{Acknowledgements}

Table 1 Total phenols, flavonoids concentration and antioxidant activity of plant extracts.

\begin{tabular}{llll}
\hline Plant extract & $\begin{array}{c}\text { Phenol total } \\
(\mathbf{m g} \text { GAE/100 } \mathbf{g ~ E X})^{\mathbf{a}}\end{array}$ & $\begin{array}{c}\text { Flavonoid total } \\
(\mathbf{m g} \mathbf{Q E} / \mathbf{1 0 0} \mathbf{g ~ E X})^{\mathbf{b}}\end{array}$ & $\begin{array}{c}\text { Radical clearance } \\
\text { DPPH } \mathbf{I C 5 0}\end{array}$ \\
\hline Fumaria officinalis & $64.10 \pm 1.77$ & $18.13 \pm 2.27$ & $122.3 \pm 8.57$ \\
Rosa Damascene & $51.05 \pm 2.50$ & $13.84 \pm 0.98$ & $148.14 \pm 13.20$ \\
Stachys lavandulifolia & $40.50 \pm 1.43$ & $11.53 \pm 0.55$ & $189.10 \pm 17.96$ \\
Salvia hydrangea & $16.05 \pm 2.29$ & $8.84 \pm 0.83$ & $234.63 \pm 13.73$ \\
\hline
\end{tabular}

The results were calculated as Mean \pm SEM.

a. milligrams of Gallic acid equivalents per 100 grams' extract

b. milligrams of Quercetin equivalents per 100 grams' extract

Table 2 The percentage of glycation inhibition expressed as TBA, DNPH and Congo red in different concentration of plant extracts as

\begin{tabular}{|c|c|c|c|c|}
\hline \multirow[t]{4}{*}{ Plant extract } & \multicolumn{4}{|c|}{ Inhibition $(\%)$} \\
\hline & \multicolumn{4}{|c|}{ Concentration (gr/dl) } \\
\hline & 0.5 & 0.25 & 0.12 & $\mathrm{IC}_{50}$ \\
\hline & \multicolumn{4}{|c|}{ TBA } \\
\hline Fumaria officinalis & $94.17 \pm 1.74$ & $80.56 \pm 1.83$ & $63.15 \pm 1.78$ & $1.04 \pm 0.05$ \\
\hline Rosa Damascene & $82.84 \pm 1.99$ & $70.43 \pm 1.87$ & $49.40 \pm 1.74$ & $1.20 \pm 0.02$ \\
\hline Stachys lavandulifolia & $67.98 \pm 2.33$ & $62.65 \pm 1.42$ & $42.38 \pm 3.09$ & $1.29 \pm 0.03$ \\
\hline \multirow[t]{2}{*}{ Salvia hydrangea } & $48.21 \pm 1.43$ & $36.35 \pm 1.91$ & $29.06 \pm 2.68$ & $1.66 \pm 0.02$ \\
\hline & \multicolumn{4}{|c|}{ DNPH } \\
\hline Fumaria officinalis & $60.34 \pm 2.13$ & $47.92 \pm 2.5$ & $37.69 \pm 1.72$ & $1.44 \pm 0.02$ \\
\hline Rosa Damascene & $45.16 \pm 2.17$ & $39.10 \pm 1.85$ & $31.11 \pm 2.14$ & $1.75 \pm 0.08$ \\
\hline Stachys lavandulifolia & $37.63 \pm 3.20$ & $27.99 \pm 2.01$ & $24.74 \pm 1.84$ & $2.07 \pm 0.32$ \\
\hline \multirow[t]{2}{*}{ Salvia hydrangea } & $25.32 \pm 1.86$ & $20.22 \pm 1.37$ & $18.01 \pm 1.61$ & $2.91 \pm 0.15$ \\
\hline & \multicolumn{4}{|c|}{ Congo red } \\
\hline Fumaria officinalis & $93.56 \pm 2.86$ & $84.08 \pm 2.39$ & $73.25 \pm 1.81$ & $0.002 \pm 0.002$ \\
\hline Rosa Damascene & $72.16 \pm 1.85$ & $58.08 \pm 3.00$ & $47.19 \pm 3.49$ & $1.27 \pm 0.30$ \\
\hline Stachys lavandulifolia & $58.94 \pm 4.45$ & $49.06 \pm 2.85$ & $44.49 \pm 2.21$ & $1.41 \pm 0.50$ \\
\hline Salvia hydrangea & $64.67 \pm 3.78$ & $54.5 \pm 3.53$ & $48.34 \pm 1.73$ & $1.28 \pm 0.01$ \\
\hline
\end{tabular}

The results were calculated as Mean \pm SEM. 
Table 3 Total inhibition of albumin glycation obtained from TBA, DNPH and Congo red tests

\begin{tabular}{lcccc}
\hline Plant extract & \multicolumn{4}{c}{ IC $_{\mathbf{5 0}}$} \\
\cline { 2 - 5 } & \multicolumn{4}{c}{ Glycation inhibition reaction assay } \\
\cline { 2 - 5 } & TBA & DNPH & Congo red & total Inhibition \\
\hline Fumaria officinalis & $1.04 \pm 0.05$ & $1.44 \pm 0.02$ & $0.002 \pm 0.002$ & $0.83 \pm 0.01$ \\
Rosa Damascene & $1.20 \pm 0.02$ & $1.75 \pm 0.08$ & $1.27 \pm 0.03$ & $1.41 \pm 0.01$ \\
Stachys lavandulifolia & $1.29 \pm 0.03$ & $2.07 \pm 0.32$ & $1.41 \pm 0.05$ & $1.59 \pm 0.10$ \\
Salvia hydrangea & $1.66 \pm 0.02$ & $2.91 \pm 0.15$ & $1.28 \pm 0.01$ & $1.95 \pm 0.05$ \\
\hline
\end{tabular}

The results were calculated as Mean \pm SEM.

Table 4 Correlation coefficients of TBA, DNPH, Congo red and total glycation inhibition with antioxidant capacity (DPPH)

\begin{tabular}{ll}
\hline & $\begin{array}{l}\text { DPPH } \\
\text { scavenging }\left(\mathbf{I C}_{\mathbf{5 0}}\right)\end{array}$ \\
\hline TBA $\left(\mathbf{I C}_{\mathbf{5 0}}\right)$ & $\begin{array}{l}\text { Cocfficient (probability) } \\
\mathrm{r}=0.931^{*} \\
P=0.000 * *\end{array}$ \\
DNPH $\left(\mathbf{I C}_{\mathbf{5 0}}\right)$ & $\mathrm{r}=0.920 *$ \\
& $P=0.000 * *$ \\
Congo red $\left(\mathbf{I C}_{\mathbf{5 0}}\right)$ & $\mathrm{r}=0.677 *$ \\
& $P=0.016 * *$ \\
Total Antiglycation $\left(\mathbf{I C}_{\mathbf{5 0}}\right)$ & $\mathrm{r}=0.917 *$ \\
& $P=0.000 * *$
\end{tabular}

* Whatever the correlation coefficient is closer to 1 , more correlation is observed between properties ** Significant correlation between variants $(\mathrm{P}<0.05)$.

Table 5 Correlation coefficients of total phenolic and flavonoids with DPPH-radical scavenging and antiglycation capacity

\begin{tabular}{lll}
\hline & \multicolumn{1}{c}{$\begin{array}{c}\text { Total phenol } \\
\text { Coefficient }\end{array}$} & $\begin{array}{c}\text { Total flavonoid } \\
\text { probability) }\end{array}$ \\
\hline DPPH-scavenging $\left(\mathbf{I C}_{\mathbf{5 0}}\right)$ & $\mathrm{r}=-0.947^{*}$ & $\mathrm{r}=-0.902^{*}$ \\
& $P=0.000 * *$ & $P=0.001 * *$ \\
TBA $\left(\mathbf{I C}_{\mathbf{5 0}}\right)$ & $\mathrm{r}=-0.980^{*}$ & $\mathrm{r}=-0.839 *$ \\
& $P=0.000 * *$ & $P=0.001 * *$ \\
DNPH $\left(\mathbf{I C}_{\mathbf{5 0}}\right)$ & $\mathrm{r}=-0.962^{*}$ & $\mathrm{r}=-0.843 *$ \\
& $P=0.000 * *$ & $P=0.001 * *$ \\
Congo red $\left(\mathbf{I C}_{\mathbf{5 0}}\right)$ & $\mathrm{r}=-0.674^{*}$ & $\mathrm{r}=-0.797 *$ \\
& $P=0.016^{*} *$ & $P=0.002 * *$ \\
Total antiglycation $\left(\mathbf{I C}_{\mathbf{5 0}}\right)$ & $\mathrm{r}=-0.944^{*}$ & $\mathrm{r}=-0.920^{*}$ \\
& $P=0.000 * *$ & $P=0.000 * *$ \\
\hline
\end{tabular}

*Whatever the correlation coefficient is closer to -1 , higher correlation is observed between properties ** Significant correlation between variants $(\mathrm{P}<0.05)$. 


\section{References}

1. Janghorbani M, Van Dam RM, Willett WC, Hu FB. Systematic review of type 1 and type 2 diabetes mellitus and risk of fracture. Am J Epidemiol. 2007;166:495-505.

2. Ghadermazi R, Khoshjou F, Hossini Zijoud SM, Behrooj $\mathrm{H}$, Kheiripour N, Ganji M, et al. Hepatoprotective effect of tempol on oxidative toxic stress in STZ-induced diabetic rats. Toxin Rev. 2017; 37(1): 1-5.

3. Cade WT. Diabetes-related microvascular and macrovascular diseases in the physical therapy setting. Phys Ther. 2008;88(11):1322-35.

4. Lee $\mathrm{P}, \mathrm{Wu} \mathrm{X}$. Modifications of human serum albumin and their binding effect. Curr Pharm Des. 2015;21(14):1862-5.

5. Anguizola J, Matsuda R, Barnaby OS, Hoy K, Wa C, DeBolt E, et al. Glycation of human serum albumin. Clin Chim Acta. 2013;425:64-76.

6. Singh VP, Bali A, Singh N, Jaggi AS. Advanced glycation end products and diabetic complications. Korean J Physiol Pharmacol. 2014;18(1):1-14.

7. Garcia $\mathbb{Z}$ Martinez R, Caraceni P, Bernardi M, Gines P, Arroyo V, Jalan R. Albumin: pathophysiologic basis of its role in the treatment of cirrhosis and its complications. Hepatology. 2013;58(5):1836-46.

8. Peng X, Zheng Z, Cheng K-W, Shan F, Ren G-X, Chen $F$, et al. Inhibitory effect of mung bean extract and its constituents vitexin and isovitexin on the formation of advanced glycation endproducts. Food Chem. 2008; 106(2): 475-81

9. Javidnia K, Mojab F, Mojahedi S. Chemical constituents of the essential oil of Stachys lavandulifolia Vahl from Iran. Iran J Pharm Res. 2004;3:61-3.

10. Perry NS, Bollen C, Perry EK, Ballard C. Salvia for dementia therapy: review of pharmacological activity and pilot tolerability clinical trial. Pharmacol Biochem Behav. 2003;75(3):651-9.

11. Nickavar B, Abolhasani L. Bioactivity-guided separa-

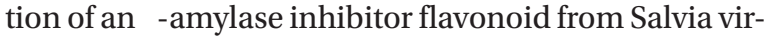
gata. Iran J Pharm Res. 2013;12(1):57-61.

12. Gholamhoseinian A, Fallah H, Sharifi far F. Inhibitory effect of methanol extract of Rosa damascena Mill. flowers on a-glucosidase activity and postprandial hyperglycemia in normal and diabetic rats. Phytomedicine. 2009;16(10):935-41.

13. Fathiazad F, Hamedeyazdan S, Khosropanah MK, Khaki A. Hypoglycemic activity of Fumaria parviflora in streptozotocin-induced diabetic rats. Adv Pharm Bull. 2013;3(1):207-10.

14. Nasri H, Shirzad H, Baradaran A, Rafieian-kopaei M. Antioxidant plants and diabetes mellitus. J Res Med Sci. 2015;20(5):491.

15. Ravan AP, Shafiei G, Eftekharian MM, Azizi A, Roshanaei G, Goudarzi F, et al. Inhibition of albumin glycation at different stages by four anti-diabetic plant extracts correlates with polyphenols and antioxidant capacity in vitro. Br J Pharm Res. 2016;12(2):1-8.

16. Tupe RS, Sankhe NM, Shaikh SA, Kemse NG, Khaire AA, Phatak DV, et al. Nutraceutical properties of dietary plants extracts: Prevention of diabetic nephropathy through inhibition of glycation and toxicity to erythrocytes and HEK293 cells. Pharm Biol. 2015;53(1):40-50.

17. Sefi M, Fetoui H, Makni M, Zeghal N. Mitigating effects of antioxidant properties of Artemisia campestris leaf extract on hyperlipidemia, advanced glycation end products and oxidative stress in alloxan-induced diabetic rats. Food Chem Toxicol. 2010;48(7):1986-93.

18. McPherson JD, Shilton BH, Walton DJ. Role of fructose in glycation and cross-linking of proteins. Biochemistry. 1988;27(6):1901-7.

19. Uchida K, Kanematsu M, Sakai K, Matsuda T, Hattori N, Mizuno Y, et al. Proc Natl Acad Sci U S A. Proceedings of the National Academy of Sciences. 1998;95:4882-7.

20. Tupe RS, Sankhe NM, Shaikh SA, Phatak DV, Parikh JU, Khaire AA, et al. Aqueous extract of some indigenous medicinal plants inhibits glycation at multiple stages and protects erythrocytes from oxidative damage-an in vitro study. J Food Sci Technol. 2015;52(4):1911-23.

21. Sadowska-Bartosz I, Bartosz G. Prevention of protein glycation by natural compounds. Molecules. 2015;20(2):3309-34.

22. Giacco F, Brownlee M. Oxidative stress and diabetic complications. Circ Res. 2010;107(9):1058-70.

23. Lobo V, Patil A, Phatak A, Chandra N. Free radicals, antioxidants and functional foods: Impact on human health. Pharmacogn Rev. 2010;4(8):118.

24. Ivanov I, Vrancheva R, Marchev A, Petkova N, Aneva I, Denev P, et al. Antioxidant activities and phenolic compounds in Bulgarian Fumaria species. Int J Curr Microbiol Appl Sci. 2014;3(2):296-306.

25. Ginova A, Mihalev K, Kondakova V. Antioxidant Capacity of petals and leaves from different rose (Rosa damascena Mill) Plantations in Bulgaria. Int J Pure App Biosci. 2013;1(2):38-43.

26. Rahimi Khoigani S, Rajaei A, Goli SA. Evaluation of antioxidant activity, total phenolics, total flavonoids and LC-MS/MS characterisation of phenolic constituents in Stachys lavandulifolia. Nat Prod Res. 2017;31(3):355-8.

27. Zarei A, Vaezi G, Malekirad AA, Abdollahi M. Effects of ethanol extract of Salvia hydrangea on

hepatic and renal functions of streptozotocin-induced diabetic rats. Avicenna J Phytomed. 2015;5(2):138-147.

28. Omodanisi EI, Aboua YG, Oguntibeju OO. Assessment of the anti-hyperglycaemic, anti-

inflammatory and antioxidant activities of the methanol extract of Moringa oleifera in diabetes-

induced nephrotoxic male wistar rats. Molecules. 2017;22(4):439.

29. Gkogkolou P, Böhm M. Advanced glycation end products: Key players in skin aging?

Dermatoendocrinol. 2012;4(3):259-70.

30. Seneviratne C, Dombi GW, Liu W, Dain JA. In vitro glycation of human serum albumin by dihydroxyacetone and dihydroxyacetone phosphate. Biochem Biophys Res Commun. 2012;417(2):817-23.

31. Rondeau P, Bourdon E. The glycation of albumin: structural and functional impacts. Biochimie. 2011;93(4):645-58. 
32. Ho S-C, Wu S-P, Lin S-M, Tang Y-L. Comparison of anti-glycation capacities of several herbal infusions with that of green tea. Food Chem. 2010;122(3):768-74.

33. Yeh W-J, Hsia S-M, Lee W-H, Wu C-H. Polyphenols with antiglycation activity and mechanisms of action: A review of recent findings. J Food Drug Anal. 2017;25(1):84-92.

34. Kaewnarin K, Niamsup H, Shank L, Rakariyatham N. Antioxidant and antiglycation activities of some edible and medicinal plants. Chiang Mai J Sci. 2014;41(1):105-16.

35. Chen Y-F, Roan H-Y, Lii C-K, Huang Y-C, Wang T-S. Relationship between antioxidant and antiglycation ability of saponins, polyphenols, and polysaccharides in Chinese herbal medicines used to treat diabetes. J Med Plant Res. 2011;5(11):2322-31.

36. Grzegorczyk-Karolak I, Gołąb K, Gburek J, Wysoki冈ska H, Matkowski A. Inhibition of Advanced Glycation End-Product Formation and Antioxidant Activity by Extracts and Polyphenols from Scutellaria alpina L. and S. altissima L. Molecules. 2016;21(6):739.

37. Rahzani K, Malekirad AA, Zeraatpishe A, Hosseini N, Seify SMR, Abdollahi M. Anti-oxidative stress activity of Stachys lavandulifolia aqueous extract in human. Cell J. 2013;14(4):314. 